\title{
The Review on MaaS Application Methods for Smart Cities
}

\author{
Seunghyun $\mathrm{Kim}^{1}$, Jongin $\mathrm{Won}^{2}$, Jooyoung $\mathrm{Kim}^{3}$ and Seungjae $\mathrm{Lee}^{4^{*}}$ \\ ${ }^{1,2}$ Department of Transportation Engineering, University of Seoul, South Korea \\ ${ }^{3}$ Integrated Urban Research Center, University of Seoul, South Korea \\ ${ }^{4 *}$ Department of Transportation Engineering, University of Seoul, South Korea \\ ${ }^{1}$ Comeback883@hanmail.net, ${ }^{2}$ whddls@naver.com, ${ }^{3}$ trafficplan@naver.com, \\ ${ }^{4}$ sjlee@uos.ac.kr
}

\begin{abstract}
Recently, the Sharing economy has been widely spread as an alternative for social phenomena such as economic depression, stagnation, environmental pollution, continuously slow growth, etc. In the transportation sector, in particular, starting from carsharing or carpooling, it is expanding to Smart Mobility in Smart Cities owing to technological developments called the Fourth Industrial Revolution. Through the changes in economic paradigm switching from possession to sharing and technological development, a new form of smart cities is expected to develop. Along with the changes in the paradigm of the market economy, the world is paying attention to the potential values of Smart Mobility and MaaS. The ultimate purpose of the smart mobility in smart cities is to resolve traffic congestion and traffic jams in a downtown. For this purpose, it is necessary to induce personal car users to use public transportation by improving convenience in public traffic, car-sharing, and personal mobility through MaaS in smart cities. By doing so, modal share of public transportation will increase and use of personal cars will decrease. Due to these reasons, MaaS takes a great role for smart cities. This study reviewed the previous research papers. Based on the reviews, it investigates specific application plans and strategies of MaaS in the smart cities.
\end{abstract}

Keywords: Smart city, Smart mobility, MaaS (Mobility as a Service), Public transportation, Application plans and strategies

\section{Introduction}

It was 1984 when Martin L. Weitzman of Harvard University used the term, "Sharing Economy" first in his thesis titled The Share Economy-Conquering Stagflation. After that, in 2008, Lawrence Lessig of the same university defined it as "regulated not by price, but by a complex set of social relations". Lessig also established the concept of the term through various cases by suggesting that it is similar to renting like an "Indian giver", not possessing product or service (Lessig, 2008).

The Sharing economy was first mentioned in the capitalistic economy of the 20th century. However, it has been widely spread as an alternative for social phenomena such as economic depression, stagnation, environmental pollution, continuously slow growth, etc. In the transportation sector, in particular, starting from car-sharing or carpooling, it is expanding to Smart Mobility in Smart Cities owing to technological developments called the Fourth Industrial Revolution. Pereira of the Technical University of Denmark defined the Smart Mobility as follows.

Received (May 16, 2018), Review Result (June 6, 2018), Accepted (July 30, 2018)

* Corresponding Author 
"The Smart Mobility combines new sensing technologies with advanced modeling and prediction tools to create applications to make our transportation systems more responsive to demand and adaptive to supply constraints (Pereira, 2017)."

He stated in 'Smart Transportation Alliance' that such Smart Mobility technology is an essential element for Smart cities.

"All around the world people are thronging cities. 53\% of the population currently lives in urban areas and by 2050 this number is expected to reach $67 \%$. Countless studies have stood out that most cities are badly equipped to cope with the transportation challenges ahead. In addition to the increasing demand for urban mobility, needs are evolving. Changing travel habits, the rise of collaborative mobility, the demand for services to increase convenience, speed and predictability, as well as evolving customer expectations towards customisation, will require more intelligent infrastructure able to cope with these extended mobility requirements. The equation is clear: there cannot be Smart cities without Smart Mobility, and no Smart Mobility is possible without Smart Infrastructure (STA, 2018)."

In order to implement the Smart Mobility, the core concept recently emerging is Mobility as a Service (MaaS). MaaS is "the integration of various forms of transport services into a single mobility service accessible on demand (MaaS alliance, 2017)."

"The transportation market is transforming owing to a convergence of trends. Shifting demographic, Social preferences, technologies and regulation are enabling multiple new solutions to move people and goods (Briggs, 2018)" by Bank of America Merrill Lynch's study.

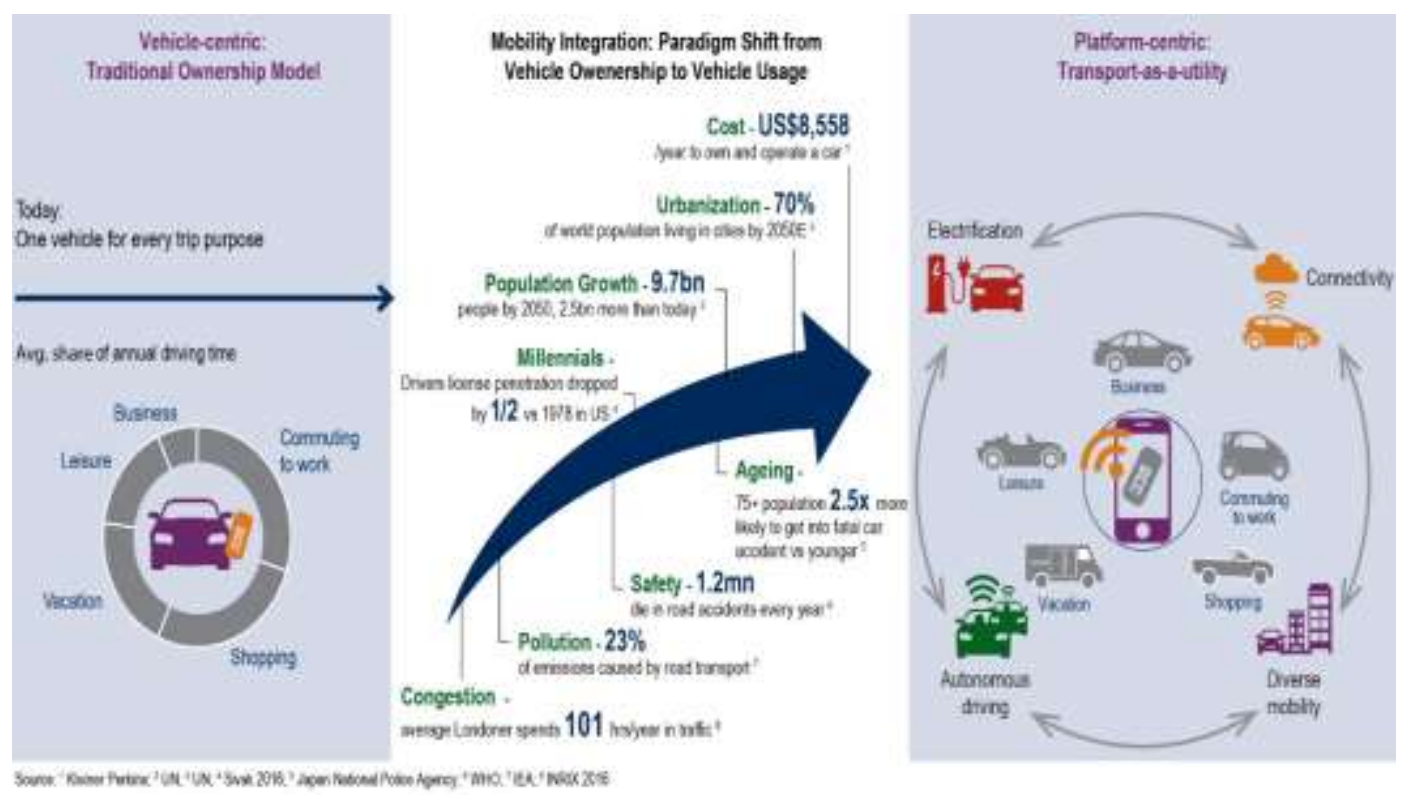

Source : Global Research 2018, Bank of America Merrill Lynch

\section{Figure 1. Expansion of the Sharing Economy and Potential Values of MaaS}

Along with the changes in the paradigm of the market economy, the world is paying attention to the potential values of Smart Mobility and MaaS. Through the changes in economic paradigm switching from possession to sharing and technological development, a new form of smart cities is expected to develop.

This study investigates specific application plans and strategies of MaaS in the smart cities in recent times. 


\section{Background}

\subsection{Smart Cities}

There is no universally accepted definition of a smart city. It means different things to different people. The conceptualization of a smart city, therefore, varies from city to city and country to country, depending on the level of development, willingness to change and reform, and resources and aspirations of the city residents. The term was first used in 1990s. At that time, the focus was on the significance of new ICT with regard to modern infrastructures within cities. The California Institute for Smart Communities was among the first to focus on how communities could become smart and how a city could be designed to implement information technologies (Alawadhi et al., 2012). Since then, Smart cities has been defined by many people in different ways. Here are some examples.

"Smart cities as a high-tech intensive and advanced city that connects people, information and city elements using new technologies in order to create a sustainable, greener city, competitive and innovative commerce, and an increased life quality (Bakic1 et al., 2012)."

"A city is smart when investments in human and social and traditional (transport) and modern (ICT) communication infrastructure fuel sustainable economic growth and a high quality of life, with a wise management of natural resources, through participatory governance (Caragliu et al., 2011)."

"Smart Cities initiatives try to improve urban performance by using data, information and information technologies (IT) to provide more efficient services to citizens, to monitor and optimize existing infrastructure, to increase collaboration among the different economic actors, and to encourage innovative business models in both the private and public sectors (Marsal-Llacuna et al., 2014)."

\subsection{Smart Mobility}

As mentioned before, Smart Mobility "combines new sensing technologies with advanced modeling and prediction tools to create applications to make our transportation systems more responsive to demand and adaptive to supply constraints (Pereira, 2017)". Aarhus of Aarhus University in Denmark is studying Smart Mobility for the following purpose.

"Smart Mobility is an Aarhus-based project that tries to solve the problems of increasing urban traffic in the city brought on by the city's growth, by making various behaviour affecting projects. The goal is to get insight on how citizens behave in traffic and to explore alternative ways of making urban traffic more effective and sustainable (Smart Aarhus, 2018).

Analyzing personal transport information (taxi/car, etc.,) based on big data, he extracts the pattern of demands of transportation users. Utilizing the result, he provides an integrated mobility service that enables personal users to make reservations as well as use and pay information through customized guidance on the existing public transport means and connecting Demand Responsive Transit (DRT). Through this, studies of smart mobility have been actively conducted worldwide aiming to convert potential car users to public transportation users.

According to the reports by the European Commission, technology and services of Smart Mobility consist of public transport services, sharing and short-term rental, MaaS, mobilityon-demand, autonomous transportation systems, smart mobility services in freight and logistics, data analytics and governance, etc., (Lennert et al., 2017). 


\subsection{MaaS (Mobility as a Service)}

Recently, car sharing market size was over USD 1.5 billion in 2017, with fleet size of over 100,000 in the same year. The number of members is forecasted to grow at over $20 \%$ between 2018 and 2024 according to the report of Global Market Insight (2018). As such, according to increasing sharing cars and decreasing personal cars, the concept of 'Mobility as a Service' emerges, which sees the mobility as a service, not possession.

"The concept of MaaS was first introduced as a form of new information support system provided to integrate transport and tourism in 1996. After then, this model was successfully performed in the form of a monthly fixed-rate ticket in Gothenburg, Sweden, but the service was suspended as it failed to get the government's support due to conflicts with the fee system of the public transportation. In the meantime, it was successful in making the mobility service popular through the application program called 'Whim' under the active support by Sampo Hietanen and the Finnish government in Helsinki, Finland. Subsequently the MaaS Alliance was formed in which many countries in the world participate. Lead by the EU, there has been remarkable development, including Mobinet which has similar functions of MaaS, and Mobilleo developed by Justin Whitston of the UK, the first MaaS App in the world (Lee, 2017)."

MaaS Alliance introduced MaaS as follows.

"Mobility as a Service (MaaS) is the integration of various forms of transport services into a single mobility service accessible on demand by MaaS alliance. To meet a customer's request, a MaaS operator facilitates a diverse menu of transport options, be they public transport, ride-, car- or bike-sharing, taxi or car rental/lease, or a combination thereof. For the user, MaaS can offer added value through use of a single application to provide access to mobility, with a single payment channel instead of multiple ticketing and payment operations. For its users, MaaS should be the best value proposition, by helping them meet their mobility needs and solve the inconvenient parts of individual journeys as well as the entire system of mobility services (MaaS alliance, 2018)."

MaaS Alliance also stated that diverse kinds of business models and new markets could be created according to the development of MaaS.

"A successful MaaS service also brings new business models and ways to organize and operate the various transport options, with advantages for transport operators including access to improved user and demand information and new opportunities to serve unmet demand. The aim of MaaS is to provide an alternative to the use of the private car that may be as convenient, more sustainable, help to reduce congestion and constraints in transport capacity, and can be even cheaper (MaaS Alliance, 2018)."

As shown in the following illust-rations, MaaS is currently applied in many cities in the world. As mentioned above, MaaS is a key element of smart cities and it is time to establish proper application methods and strategies. 


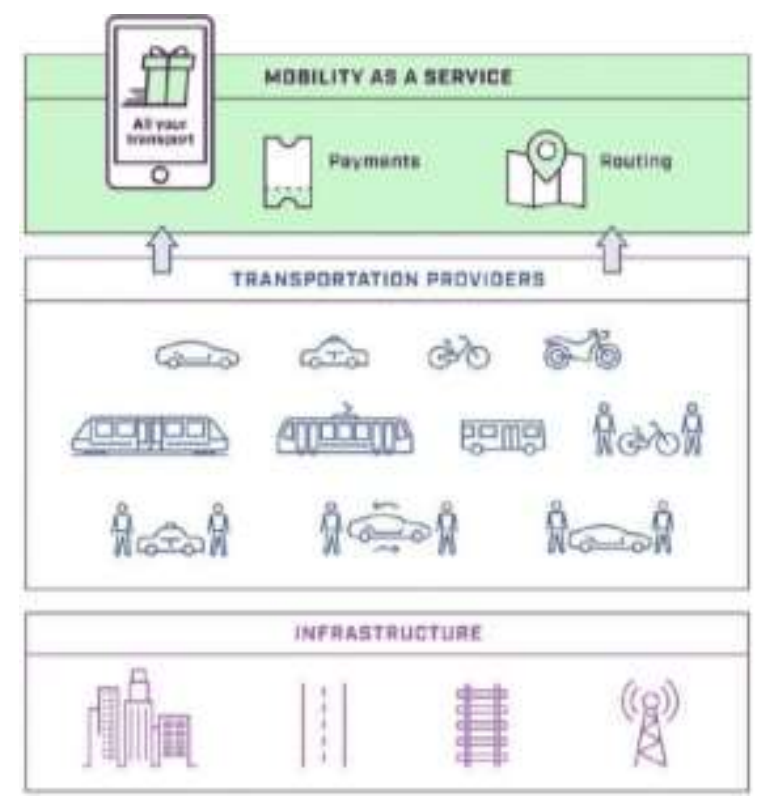

Source: https://maas.global/maas-as-a-concept/

Figure 2. The Concept of MaaS
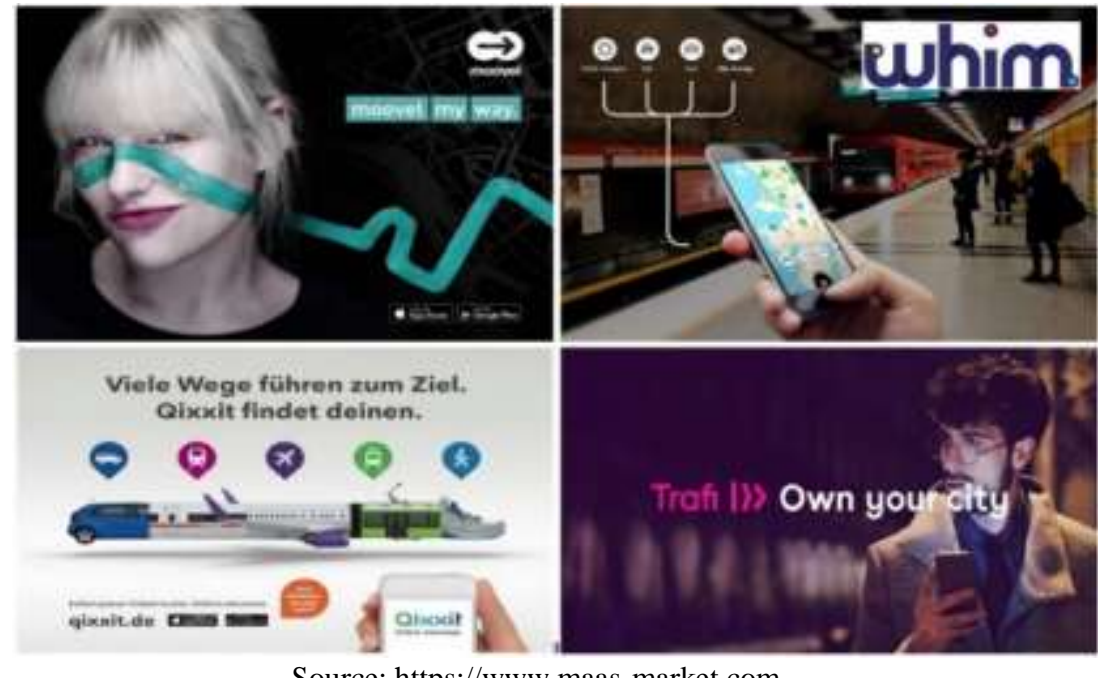

Source: https://www.maas-market.com

Figure 3. Global Business Cases of MaaS

\section{Vitalization Atrategy of MaaS for Smart Cities}

The ultimate purpose of the smart mobility in smart cities is to resolve traffic congestion and traffic jams in a downtown. Previously, cities utilized physical means to resolve such problems in the aspect of facility supply, including road construction, expansion of transportation infrastructure, and transportation system management (TSM). In the aspect of management of transportation demands, they have used traffic control and driving restriction policy in the downtown. However, such means reach limitations in most cities. Getting out of such physical or policy actions mentioned above, smart cities use state-ofthe art technologies such as IT, massive IoT sensors, and big data analysis and try to solve the problems. Therefore, it is necessary to induce personal car users to use public transportation by improving convenience in public traffic, car-sharing, and personal mobility through MaaS in smart cities. By doing so, modal share of public transportation will increase and use of personal cars will decrease. Subsequently, it will reduce traffic 
congestions due to decreasing the number of cars and bring the effects of decreasing air pollution and energy savings at the same time. Due to these reasons, MaaS takes a great role for smart cities.

This study reviewed the previous research papers. Based on the reviews, it classified the technologies and strategies required for applying MaaS to smart cities into 6 categories as follows.

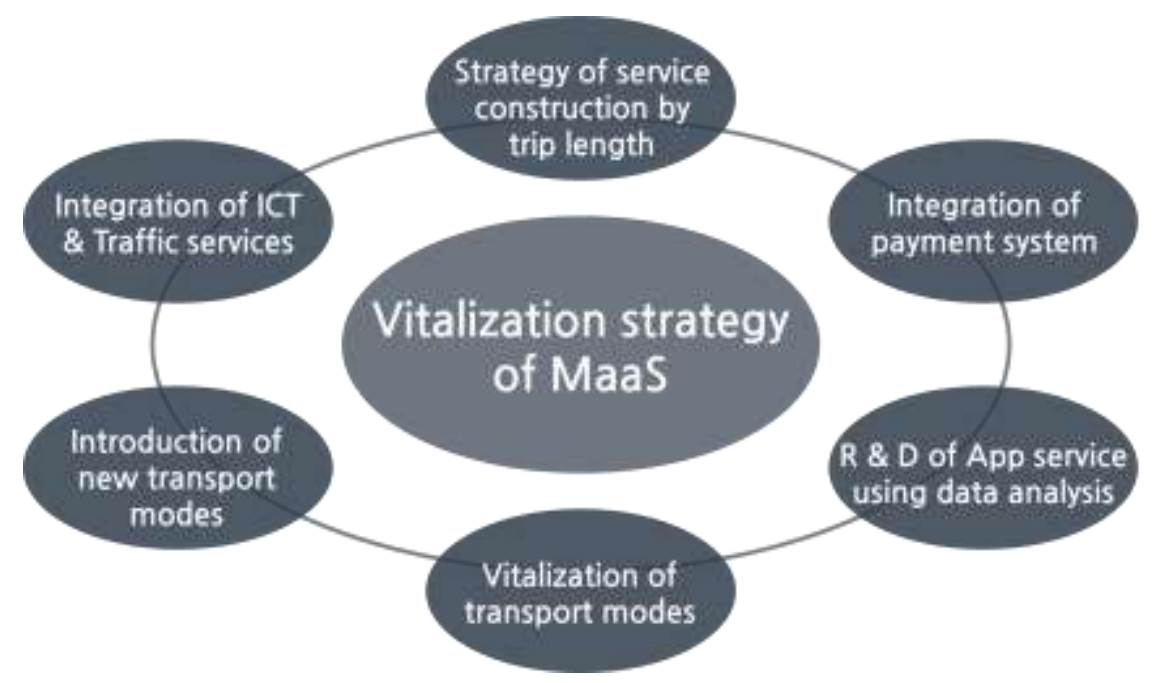

Figure 4. The Six Vitalization Strategies of MaaS

\subsection{Strategy of Service Construction by Trip Length}

Analyzing the trip volume by transport means in the internal and external bus zones in Seoul, Korea, it was found that preference of citizens on the transport means varied depending on the trip length. As for the trips within the internal bus zone, the preferences were in the order of car, bus, taxi, subway, and bustsubway. On the other hand, as for the trips between the external bus zones, the preferences were in the order of car, subway, bus+subway, bus, and taxi. In the trips within the wide-area bus zones between Seoul and Gyeonggi Province, the preferences were in the order of car, bus+subway, subway, bus, and taxi.

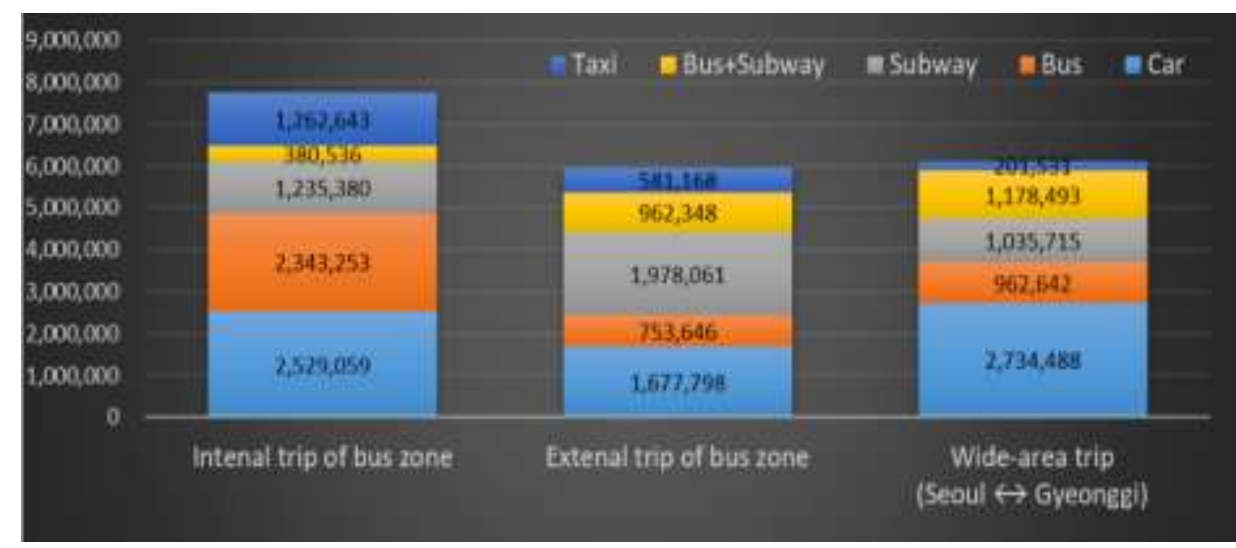

Source: The 3rd Seoul Public Transportation Master Plan (2017 2021)

\section{Figure 5. Traffic Volume by Transport Means between Bus Zones}

From the analysis results above, we could learn that the preferences for transport means and services varied according to trip length and the scale of the bus zones. Therefore, the strategies to build the MaaS should be changed according to the scale of the bus zones. 
Abhay Jain, the CEO of Active Scaler established service strategies of MaaS by classifying the scales of the MaaS into three: local, regional, and national.

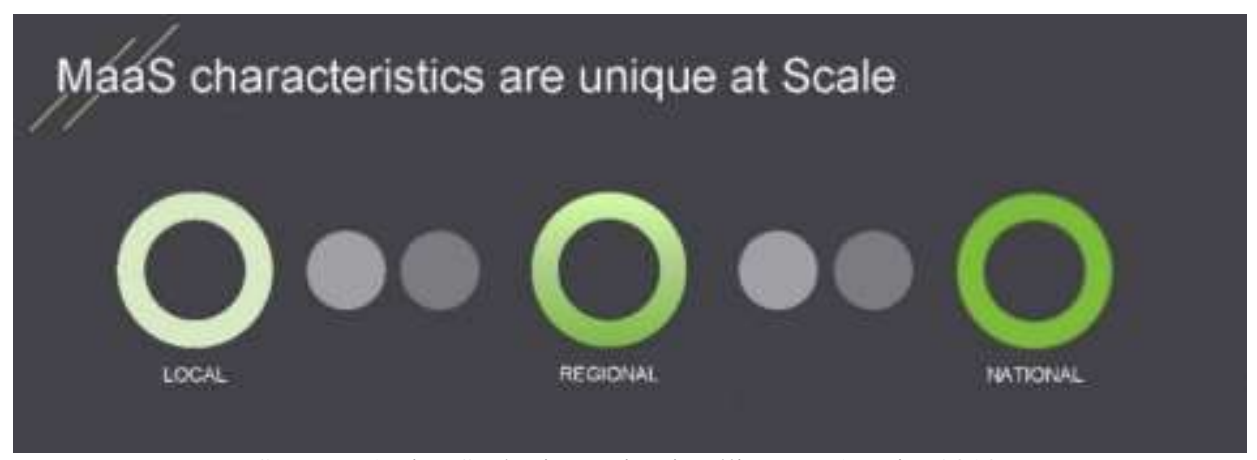

Source: Active Scaler in motion intelligence, A. Jain, 2018.

\section{Figure 6. Classification According to the Scale of MaaS Area}

At the local scale, since the trip length is short, people mainly used a single transport mode. Also, the transportation vulnerable such as seniors and children take trips mainly within a local area because they have difficulties in taking trips to other areas due to their physical restrictions. Therefore, it is required to vitalize services to solve the problems of the transportation vulnerable. Specifically, for the safe travel of seniors, the door-to-door service market of single transport mode should be vitalized. Tagsi Inc., located in the San Francisco Bay Area, USA is solving the problem of a single trip within an area by developing transport modes for children and seniors (A. Jain, 2018).

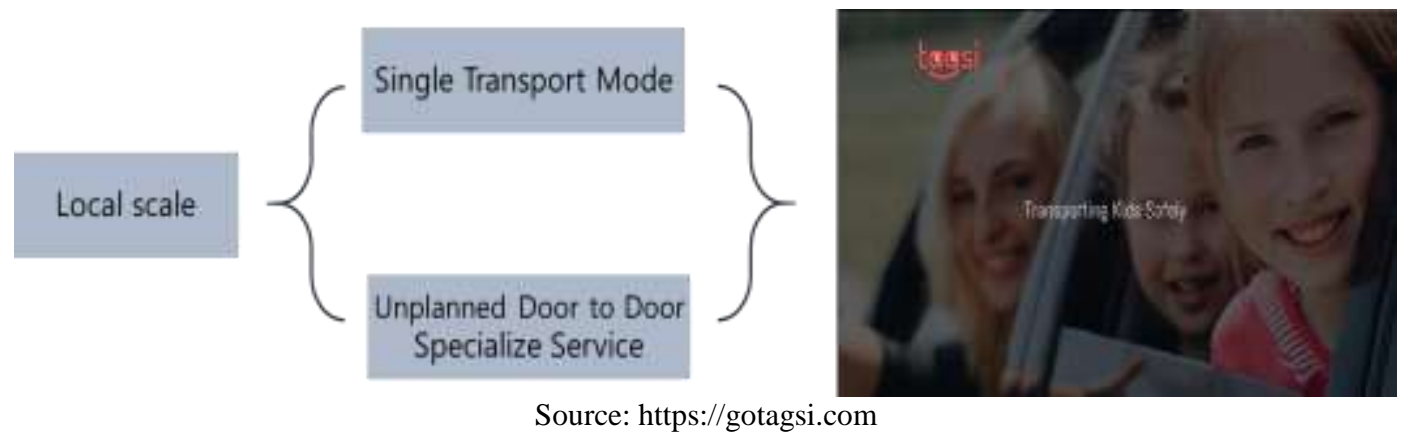

Figure 7. Planning MaaS Strategy at Local Scale

At the regional scale, the most common trip patterns were shown, which clearly identified problems occurring during trips and various plans to solve the problems that could be suggested. One of the representative trip examples at a regional scale is commuting by workers. For commuting to the workplace, multi-mode transports are used, mainly by bus or subway. The main issue is to provide first and last mile connections efficiently (A. Jain, 2018). To solve the problem, car sharing or bicycle sharing is mainly used, as well as trying to connecting with personal mobility. If these kinds of services become established and popular, the number of cars on the road would decrease and high efficiency could be obtained for trips (A. Jain, 2018). 


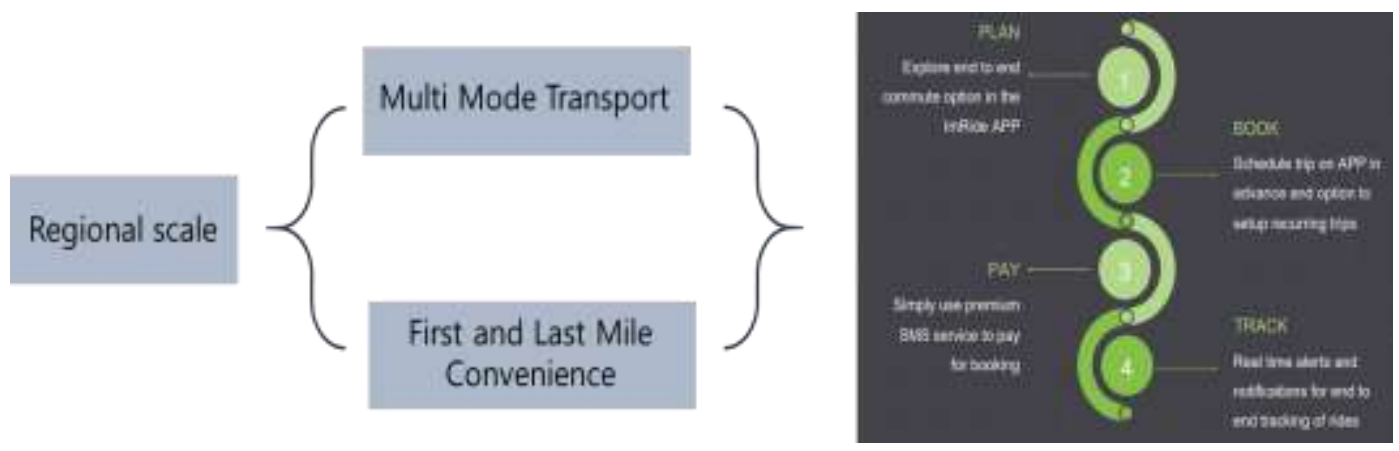

Source: Active Scaler in motion intelligence, A. Jain, 2018.

\section{Figure 8. Planning MaaS Strategy at Regional Scale}

At the national scale, common examples are travel tourism or freight transportation. They are special trip patterns that have a lot of problems to solve. However, markets for trips at the national scale are expected to be more active. Compared to the last few years, the markets have been further vitalized due to the services provided by low-price airlines. Trips at the national scale use multi-mode transport as they are long-distant trips such as high-speed rail, air plan, ship, etc., as well as public transportation. Therefore, at the national scale, it is important to vitalize planned and scheduled services, shortened trip hours and connect door-to-door service (A. Jain, 2018).

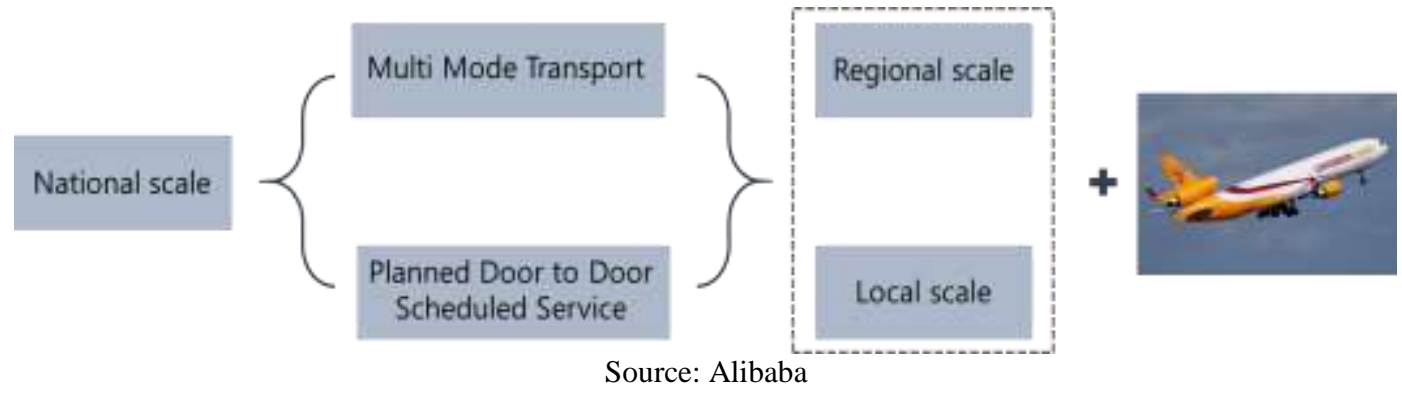

Figure 9. Planning MaaS Strategy at National Scale

\subsection{Integration of Payment System}

In MaaS, integration of payment system is essential for a seamless connection between transport modes. The feasibility study for MaaS conducted by the UCL Energy Institute illustrated the major concepts of MaaS. Registration and package selection, journey planning, booking, getting on board, and booking \& payment are the key elements in MaaS.
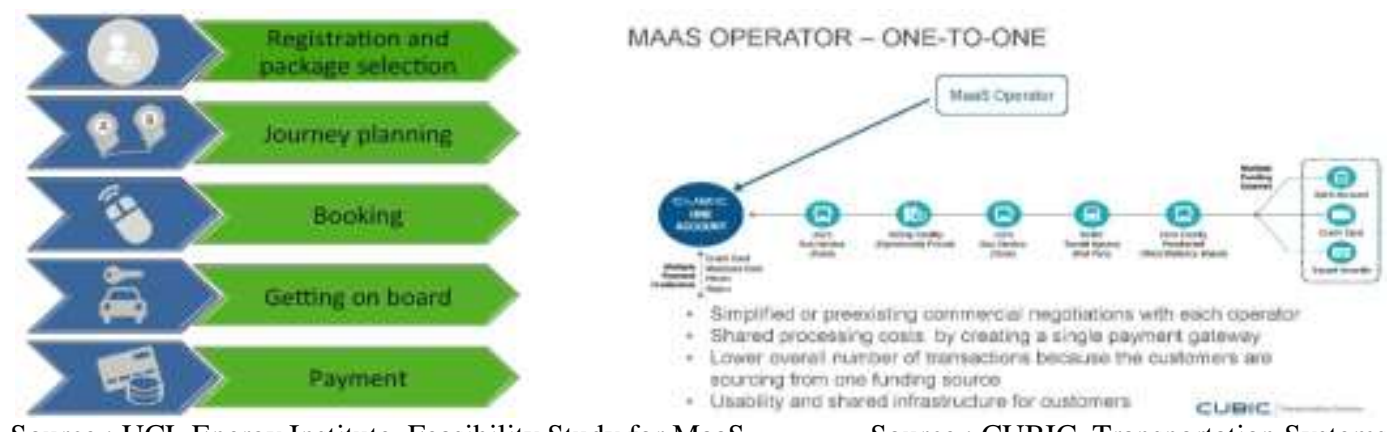

Source : UCL Energy Institute, Feasibility Study for MaaS

Source : CUBIC, Transportation Systems

Figure 10. Concept for MaaS and One-to-One Operator System 
In booking \& payment, it is important to make the system simple to book all transport services at once and pay the fee through a one-time payment action in a single account. Taylor in CUBIC stated that it is better for a single operator to operate an integrated MaaS for the following reasons:

- simplified or preexisting commercial negotiations with each operator

- shared processing costs by creating a signal payment gateway

- Lower overall number of transactions because the customers are sourcing from one funding source

- usability and shared infrastructure for customers

Another fare strategy is to provide users benefits through a discount and mileage system by connecting with an integrated fare system. In order to vitalize MaaS through the participation of many transport modes, there should be many users at the beginning stage of the service. Also, it is necessary to increase market size by providing many benefits to passenger car users. Figure 11 illustrates how users have benefits through an integrated mileage system and integrated advance payment system in Maas. Through an integrated advance payment system, MaaS provides users benefits of commutation ticket discounts, use of collected points, etc.

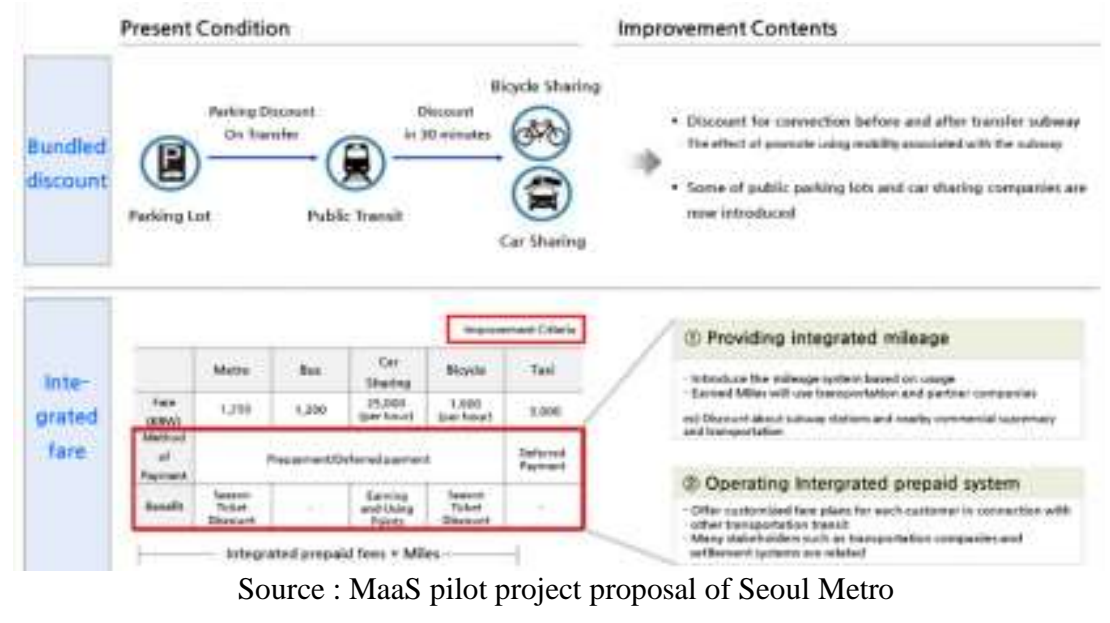

Figure 11. Example of Fare Discount \& Integration Strategy

\subsection{Research \& Development of App Service using Data Analysis}

In smart cities, data from various areas are collected and stored, including urban administration, environment, energy, transportation, living welfare, etc. The recent trend is collecting and developing various data on cities through an open-type data hub center so that citizens can utilize it (KAIA, 2017).

In order to build MaaS, it is necessary to develop technologies to collect personal trip information through traffic card data, mobile data, sensor data, etc., to share real-time operation information of transport modes, and to provide an integrated user-oriented and customized traffic service. For this purpose, new apps should be developed by utilizing data on existing transport modes. Figure 12 illustrates the service that provides optimal itinerary and transit convenience to users by connecting information on existing public transportation routes and operation with the nearby taxi information. If these apps are advanced and integrated, MaaS can be built eventually. 

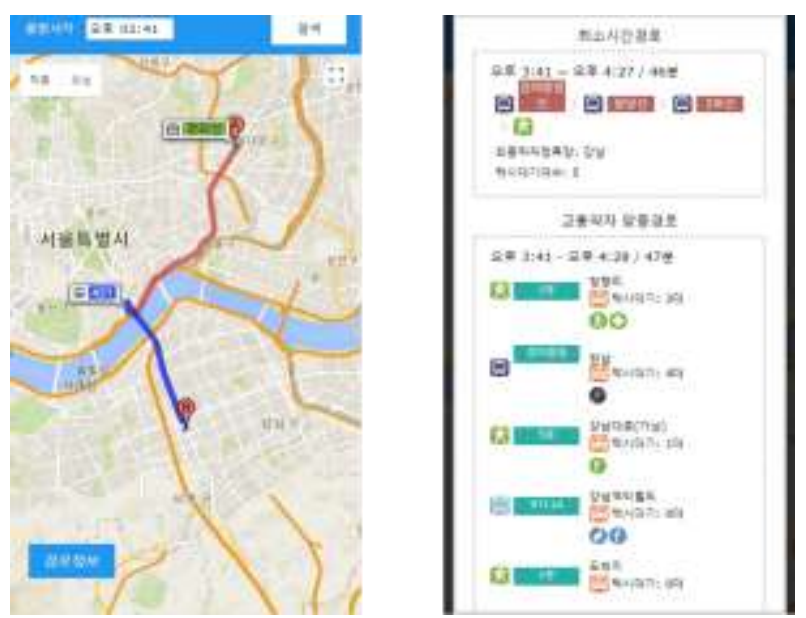

\section{Figure 12. Example of MaaS Application in Seoul, Korea}

If only traffic data is utilized in the process of developing MaaS, it is hard to reflect characteristics or needs of users who do not use public transportation. Therefore, interview surveys are necessary with those who do not use public transportation (most of them own and use their own cars) (ATKIS, 2018). Through the interviews with them, it is required to set a strategy to publicize MaaS to those who rarely use public transportation and induce them to access and use the service.

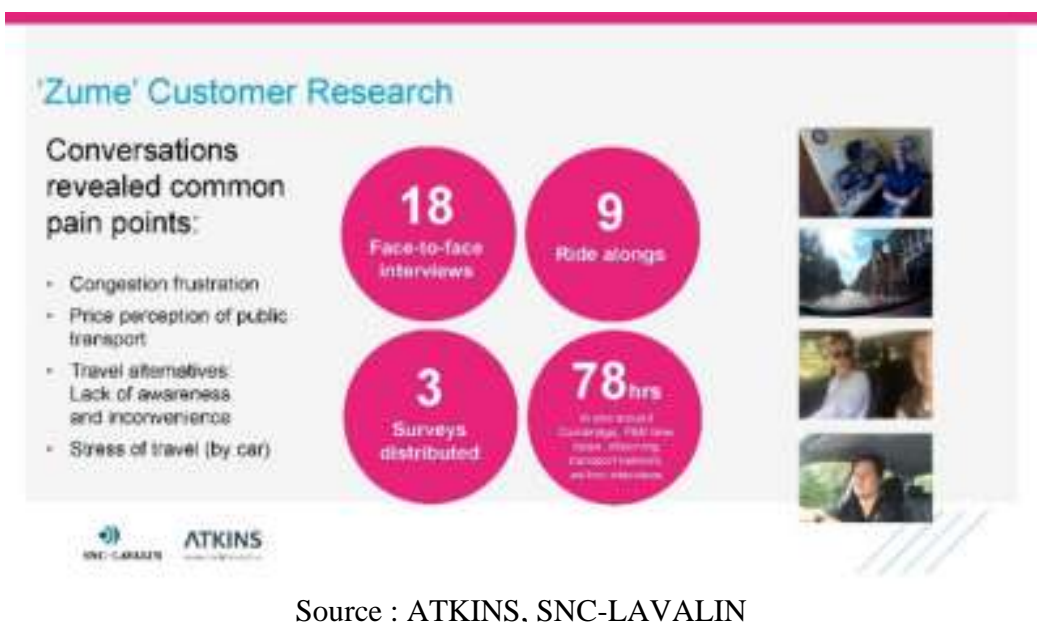

Figure 13. Customer Research \& Promotion

In the event of building MaaS with the traffic data only collected previously, the service might focus only on repetitive trips (commuting for work, etc.). In the aspect of life cycle of a person, the trip characteristics of the person would vary according to the changes in his/her occupation and status. Customized and personalized service for users should predict and reflect those factors. For example, when getting old, people need to take trips for leisure more rather than for work, and the trip patterns can be more diverse according to their religion or age (S. Hietanen, 2018). Strategies to predict the changes in personal traits of users are required by using an artificial deep learning technique. 


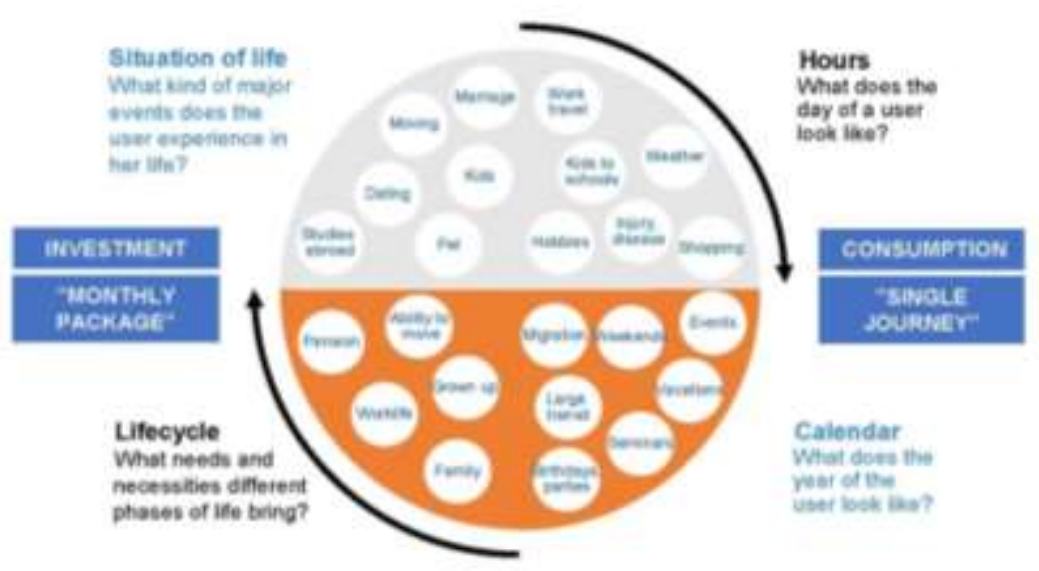

Source: MaaS global, whim

Figure 14. Life Situation and Unexpected Incidents Affecting your Daily Mobility

\subsection{Vitalization of Transport Modes}

In order to realize the seamless door-to-door service of MaaS, diverse transport modes (car sharing, bike sharing, personal mobility, etc.,) should be built, as well as basic public transport modes (bus, subway, taxi, etc.). Development stage of transport modes, however, can be different from each other according to development level of the cities or countries, geographical environment, and their other unique characteristics. Therefore, it is necessary to vitalize and progress underdeveloped transport modes so that they can be connected and accessed easily. Next to consider for MaaS is to include infrastructure that is connected to parking lots as one whole platform. The effect of MaaS will increase when diverse transport modes are combined.

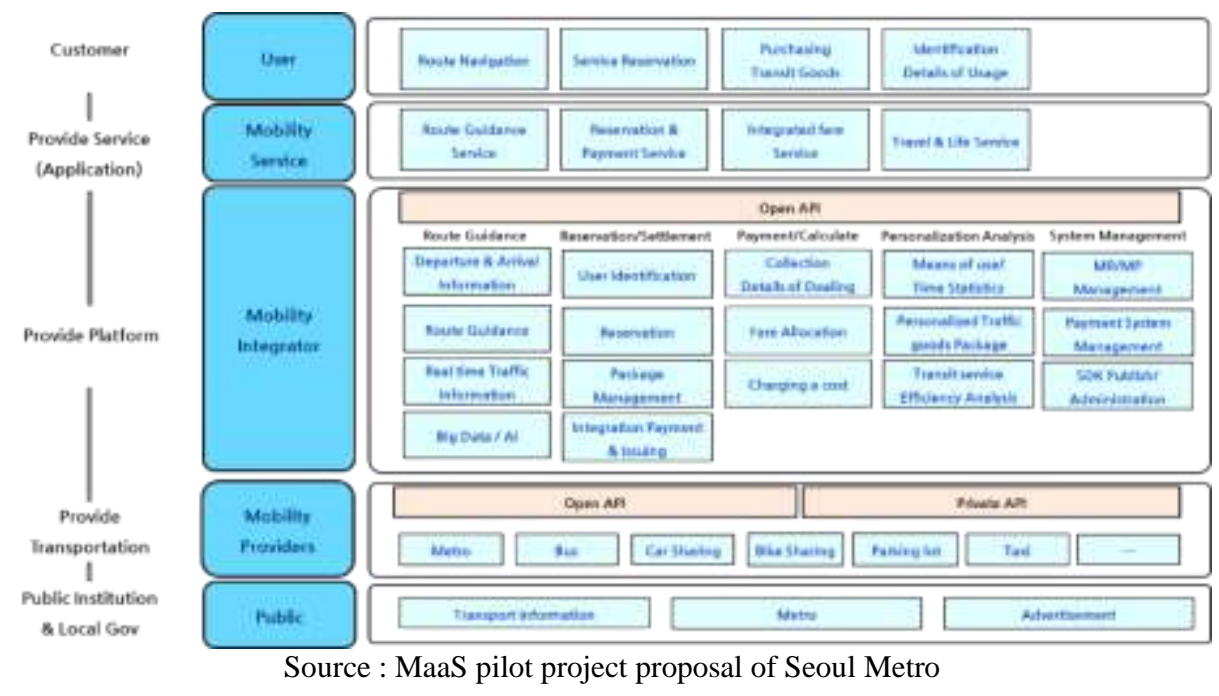

Figure 15. Platform of MaaS

\subsection{Introduction of New Transport Modes}

As mentioned above, car sharing market has grown rapidly recently. As of October 2014, 104,000 membership cars are under operation with about 400,000 members in 1,531 cities of 33 countries. Among them, Europe and the North American market occupied about $46 \%$ and 34\%, of the whole market, respectively (Shaheen \& Cohen, 2016). 
"Current autonomous vehicles are largely classified into 5 driving levels according to the technology. Most global automobile makers aim to commercialize them up to Level 3 by 2020 (W. H. Kim, 2016).”

In recent times, the two technologies are combined into one. Along with the technological development of sharing cars, they are likely to be substituted with autonomous cars in the future. Therefore, strategies to develop the service that utilizes inner space of a vehicle connected with sharing cars.
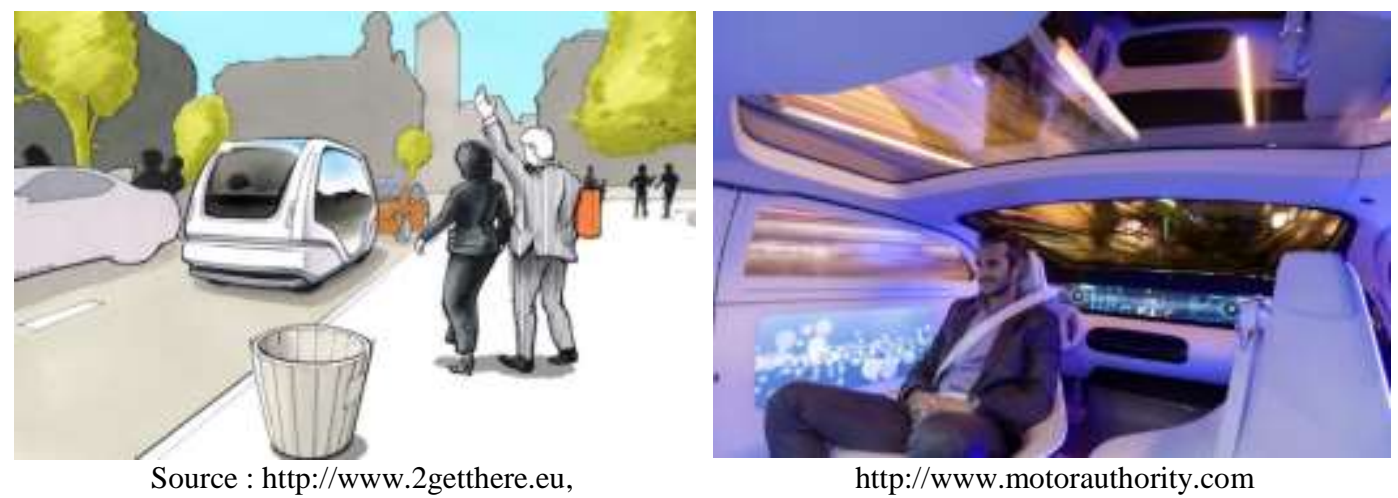

Figure 16. Shared Autonomous Vehicle

If people can do personal work and/or other activities inside the car through a shared autonomous vehicle and it is connected with MaaS, more advanced levels of MaaS can be realized. It is essential to increase autonomous vehicle competitiveness in order to convert the modes of personal cars through the technology.

\subsection{Integration of ICT \& Traffic Services}

"Cities have a complicated structure duplicated with diverse systems of transportation, energy, building, etc. Along with changes in population, local, economic and social environment, and technological development of science, various problems have occurred. However, we do not have any definite plan to solve such urban problems (KAIA, 2017)."

In order to solve such problems, various information and communication technology (ICT) are introduced to smart cities. Through various sensors and network technologies, every part and every element will be connected to one another in a city. The same applies to the transportation sector. Vehicle and vehicle will be connected; road and vehicle will be connected; and vehicle and building will be connected. If Maas is built and it connects the point of departure with the destination utilizing ICT in smart cities, more seamless, safer, faster, and more convenient services will be provided. Therefore, it is required to set a strategy to develop MaaS by combining various state-of-the-art technologies in smart cities.

Pressas et al., expected connected vehicles in Smart cities as follows.

"There is an urgent need for smart transportation, to enable safer, efficient and more enjoyable journeys, and connected vehicles are a way to realise that. Modern cars feature embedded systems that monitor and manage all the critical sensors and actuators (Pressas et al., 2016)." 


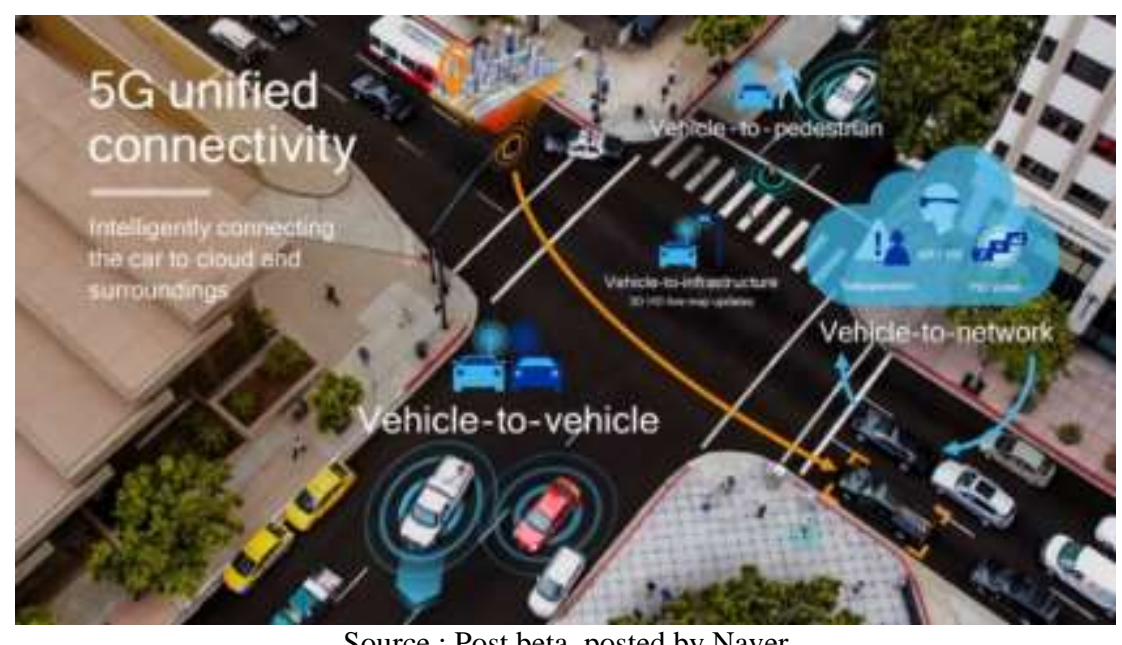

Source : Post beta, posted by Naver

Figure 17. ICT \& Connectivity of Smart Cities

\section{Conclusion}

This study reviewed many business cases of MaaS and research results. Based on this, it established the necessary strategies to build MaaS in smart cities. In order to vitalize MaaS, six strategies were set as follows: service construction by trip length; integration of payment system; R\&D of App service using data analysis; vitalization of transportation; introduction of new transport means; and integration of ICT \& traffic services.

Reviewing many cases, this study obtained the following conclusions. First, MaaS should be promoted through a public private partnership. Since the social benefit that could be obtained from the vitalization of MaaS is great, it requires large scale investment. Service and technological development in each area can be conducted by the private sector, but the project should be promoted at the national level through the integration of information. Next, MaaS should be integrated gradually from the small-sized infrastructure services, not by direct action for vitalization. In fact, many cases showed impelling progress for projects weighing too much on the potential value of MaaS. Most of them did not achieve positive effects. Integration should be made only from the level of what is possible. Then, being integrated through the cooperation between government and civil sector together for bigger social goals, a more advanced level of MaaS can be built.

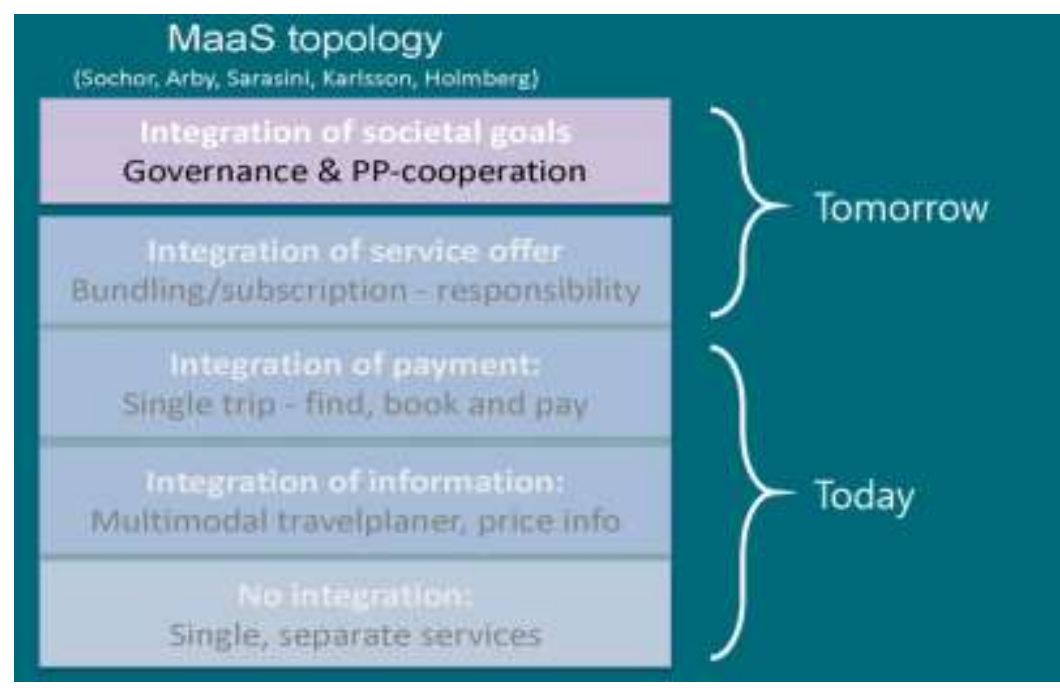

Source : Ubigo, Stockhlom and Gothenburg, http://ubigo.se/

Figure 18. Today \& Tomorrow of MaaS 


\section{Acknowledgement}

This work was supported by the Ministry of Education of the Republic of Korea and the National Research Foundation of Korea (NRF-2015S1A5B8046775).

\section{References}

[1] A. Jain, "MaaS Market-Concept to Delivery", Active Scaler, Atlanta, USA, (2018).

[2] A. Caraliu, C. Del Bo and P. Nijkamp, "Smart Cities in Euroup", Journal of Urban Technology, vol. 18 , no. 2, (2011), pp. 65-82.

[3] A. Taylor, "Building a MaaS Financial Engine", CUBIC, (2018).

[4] A. Pressas, Z. Sheng, P. Fussey and D. Lund, "Connected Vehicles in Smart Cities: Interworking from Inside Vehicles to Outside", $13^{\text {th }}$ Annual IEEE International Conference, (2016).

[5] Snc-Lavalin Atkins, "MaaS Market-Rethinking transportation”, (2018), https:// www.maasmarket.com.

[6] F. C. Pereira, "Smart Mobility", Transport DTU, Technical University of Denmark, (2017), http://www.transport.dtu.dk/english/research/cross-cutting-themes/smart-mobility-lab.

[7] Global market insights, "Car Sharing Market Trends - Global 2018-2024 Industry Size Report", (2018).

[8] Hyundai Motor Group, "MaaS pilot project proposal of Seoul Metro”, Seoul Metro, (2018).

[9] Korea Agency for Infrastructure Technology Advancement, "World Leading SmartCity R\&D Project Report", Ministry of Land, Infrastructure and Transport, (2017).

[10] L. Lessig, "REMIX-Making Art and Commerce Thrive in the Hybrid Economy", The Penguin Press, (2008).

[11] MaaS alliance, https://maas-alliance.eu/homepage/what-is-maas/, (2018).

[12] M. L. Weitzman, "The Share Economy-Conquering Stagflation”, Harvard University Press, (1984).

[13] M. Briggs, "BofAML Autos: Mobility as a Service. Will the car have a future?", Bank of America Merrill Lynch, (2018).

[14] M. L. Marsal-Llacuna, J. Colomer-linaàs and J. Meléndez-Frigola, "Lesson in urban monitoring taken from sustainable and livable cities to better address the Smart Cities initiative", Technological Forecasting and Social Change", (2014).

[15] S. Alawadhi, A. Aldama-Nalda, H. Chourabi, J. R. Gil-Garcia, S. Leung, S. Mellouli, T. Nam, T. A. Pardo, H. J. Scholl and S. Walker, "Building Understanding of Smart City Initiatives", Lecture Notes in Computer Science 7443, (2012), pp. 40-53.

[16] Seoul Metropolitan Government, "The $3^{\text {rd }}$ Seoul public transportation master plan (2017 2021)", (2017).

[17] Shaheen \& Cohen, "2016 Innovative mobility carsharing outlook", TSRC, University of California, Berkeley, (2016).

[18] S. Hietanen, "Mobility as a Service. The End of Car Ownership?', whim, (2018), https:// www.maas-market.com.

[19] Smart Aarhus, Aarhus University, Denmark, https://www.smartaarhus.eu/ projects/ smartmobility, (2018).

[20] T. Bakıc1, E. Almirall, J. Wareham, "A Smart City Initiative: The Case of Barcelona”, Journal of Knowledge Economy, vol. 2, no. 1, (2012), pp. 1-14.

[21] UCL Energy Institute, "Feasibility Study for "Mobility as a Service" concept in London", Department for Transport, UK, (2015).

[22] W. H. Kim, "Traffic in Seoul is evolving”, The Seoul Institute, (2016).

[23] Y. Lee, "MaaS (Mobility as a Service)", Chung-Ang University, https://blog.naver.com/ koti10/221116030573, (2017). 